\title{
Children and Employment - Resource or Stressors after Breast Cancer?
}

\author{
Kinder und Erwerbstätigkeit - \\ Ressource oder Belastung nach einer Brustkrebserkrankung?
}

Authors

Affiliations
K. Ebenhan ${ }^{1}$, K. Leuteritz ${ }^{1}$, Y. Barthel ${ }^{1}$, M. E. Beutel ${ }^{2}$, K. Papsdorf ${ }^{3}$, G. Weissflog ${ }^{1}$, E. Brähler ${ }^{1}$

${ }^{1}$ Department für Psychische Gesundheit, Abteilung für Medizinische Psychologie und Medizinische Soziologie Universitätsklinikum Leipzig AöR, Leipzig

${ }^{2}$ Universitätsmedizin der Johannes Gutenberg-Universität Mainz, Klinik und Poliklinik für Psychosomatische Medizin und Psychotherapie, Mainz

${ }^{3}$ Universitätsklinikum Leipzig AöR, Klinik und Poliklinik für Strahlentherapie und Radioonkologie, Leipzig

\begin{abstract}
Key words
- breast cancer

- psychological stress

- children

- time since diagnosis

- employment status

Schlüsselwörter

- Brustkrebs

- psychische Belastung

- Kinder

- Zeit seit Diagnosestellung

- Erwerbsstatus
\end{abstract}

\section{received 22.12.2012 revised 10.6.2013 accepted $\quad 4.7 .2013$}

\section{Bibliography}

DOI http://dx.doi.org/

10.1055/s-0033-1350704

Geburtsh Frauenheilk 2013; 73 :

792-799 ๔ Georg Thieme

Verlag KG Stuttgart . New York . ISSN 0016-5751

\section{Correspondence \\ Katja Ebenhan}

Abteilung für Medizinische

Psychologie und Medizinische

Soziologie Universitätsklinikum

Leipzig AöR

Department für Psychische

Gesundheit

04103 Leipzig

katja.ebenhan@gmx.de

\section{Abstract \\ $\nabla$}

Introduction: Breast cancer patients suffer clinically relevant levels of psychological stress because of their disease. Various factors can affect the level of stress experienced. This study aimed to investigate the relationship between the level of psychological stress and employment and children, including time since diagnosis.

Material and Methods: A randomised clinical study was done of 724 breast cancer patients aged between 18 and 65 years; all were in the curative stage of disease and had been diagnosed 0 12 months previously. Patients were investigated for their levels of psychological stress (anxiety and depression) using the Hospital Anxiety and Depression Scale (HADS). The relationship between anxiety and depression and the variables "employment", "parenthood" and "time since diagnosis" were investigated, using univariate and multivariate analysis.

Results: Patients with a longer time since diagnosis (4-12 months) were found to have lower levels of anxiety (6.28) compared to patients who had been diagnosed only $0-3$ months previously ( $7.24 ; p<0.01)$. There was no unambiguous relation between parenthood and anxiety. The age of the children was crucial. Even when results were controlled for patient age, the anxiety levels of women with children below the age of 16 years were significantly higher (7.84) compared to patients without children (6.42) or patients whose children were older than 16 years (6.87; $\mathrm{p}=0.04$ ). Women who were not employed had significantly higher levels of depression compared to all other participants in the study $(p=0.02)$. No reciprocal effects were found between investigated variables.

Conclusion: We found a differentiated relationship between the variables "time since diagnosis", "employment" and "children" and the level of psychological stress experienced by breast cancer

\section{Zusammenfassung}

$\nabla$

Einleitung: Brustkrebspatientinnen sind im Rahmen ihrer Erkrankung in klinisch relevantem Ausmaß psychisch belastet. Die Stärke der Belastung wird durch verschiedene Faktoren determiniert. Ziel dieser Arbeit war die Untersuchung des Zusammenhangs der psychischen Belastung mit Erwerbstätigkeit und dem Vorhandensein eigener Kinder unter Einbeziehung der Zeit seit Diagnosestellung.

Material und Methodik: Im Rahmen einer randomisierten klinischen Studie wurden 724 Brustkrebspatientinnen im Alter von 18-65 Jahren im kurativen Stadium mit einer Zeit seit Diagnosestellung von 0-12 Monaten hinsichtlich ihrer psychischen Belastung (Ängstlichkeit und Depressivität) mit der Hospital Anxiety and Depression Scale (HADS) beurteilt. In uni- und multivariaten Analysen wurde der Zusammenhang von Ängstlichkeit und Depressivität mit den Variablen Erwerbstätigkeit, Elternschaft und Zeit seit Diagnosestellung geprüft.

Ergebnisse: Patientinnen mit längerer Zeit seit Diagnosestellung (4-12 Monate) zeigen geringere Werte für Ängstlichkeit $(6,28)$ als die Patientinnen, bei denen die Diagnosestellung erst 0-3 Monate zurück liegt $(7,24 ; \mathrm{p}<0,01)$. Zwischen Elternschaft und Ängstlichkeit gibt es keinen eindeutigen Zusammenhang. Das Alter der Kinder ist entscheidend. Auch unter Kontrolle des Lebensalters der Patientinnen zeigt sich Ängstlichkeit bei Frauen mit Kindern unter 16 Jahren signifikant höher $(7,84)$ als bei kinderlosen Patientinnen $(6,42)$ oder solchen mit Kindern ab 16 Jahren $(6,87 ; p=0,04)$. Erwerbslose Frauen zeigen signifikant höhere Depressivitätswerte als alle anderen Studienteilnehmer $(p=0,02)$. Wechselwirkungen zwischen den untersuchten Variablen treten nicht auf.

Schlussfolgerung: Zwischen der Zeit seit Diagnosestellung, dem Erwerbsstatus sowie dem Vor- 
patients. When determining the level of psychological stress in the 1st year after diagnosis, particular attention should be paid to patients who are not employed and patients with children below the age of 16 years. handensein eigener Kinder und psychischen Belastung bei Brustkrebspatientinnen ergeben sich differenzielle Zusammenhänge. Bei der Erfassung der psychischen Belastung im 1. Jahr nach der Diagnosestellung sollte besondere Aufmerksamkeit auf erwerbslose Patientinnen und Patientinnen mit jüngeren Kindern gerichtet werden.

\section{Introduction}

$\nabla$

In Germany, 57000 women will develop breast cancer every year, making breast cancer by far the most common tumour in women [1]. Improvements in diagnosis and treatment in the last decades have considerably increased survival rates, but have also led to an overall increase in persons with disease. Since the 1980s, the relative 5 -year survival rate has risen from 69 to $81 \%$. The 10 -year prevalence is estimated to be 416000 [1]. These patients live with the diagnosis of breast cancer and are at higher risk of developing mental illness. The worries about disease recurrence and mortality and the negative impact on body image, femininity and sexuality mean that psychological stress may persist for many years after diagnosis, and psychological stress may reach clinically relevant levels [2-4].

To identify and support cancer patients who develop psychological co-morbidities in good time, it is important to obtain more information about the variables which can affect the severity of psychological stress. Some of the factors relating to patients and disease have been verified many times in empirical studies. A younger age and female sex are often associated with higher levels of anxiety, both in cancer patients and in the general population [5-8]. In the general population, depression is usually associated with older age $[9,10]$, but in breast cancer patients there is no definitive association with age $[4,6]$. A prior history of mental health issues is a strong predictor for higher levels of psychological stress in breast cancer patients $[11,12]$. The most important risk factors for increased levels of anxiety or depression associated with disease are functional disorders and physical symptoms such as pain or breast and arm symptoms [2,13,14].

To date, it was usually not possible to demonstrate a clear association between anxiety and depression and time since diagnosis (TsD). In a longitudinal study over 5 years, Hopwood et al. [6] investigated the course of psychological stress in 2208 breast cancer patients. In some patients, levels of anxiety and depression decreased over time; however, there were no significant differences in the proportion of patients with clinically relevant levels of anxiety or depression at various time-points after diagnosis. Similarly, in a cross-sectional study of 1083 patients with TsD between 1.5 and 5 years, Mehnert et al. [4] found no association between TsD and psychological stress. Interestingly, smaller prospective studies $[15,16]$ which investigated psychological stress immediately after diagnosis found that anxiety and depression decreased significantly in the first year after diagnosis. However anxiety levels still did not drop to the level reported for the general population; in contrast to depression levels, anxiety levels remained slightly increased.

Findings on the association between employment and psychological stress in breast cancer patients are also unclear. In the general population, being unemployed generally constitutes a risk for psychological stress [17-19]. Every 6th breast cancer patient is younger than 50 years of age and thus affected by the diagnosis at an age where work and career play important roles. We can assume that the added difficulties of simultaneously dealing with disease and the demands of work will also have an impact on mental health in these patients. Just approximately two thirds of all patients return to work after their treatment has been completed, and after cancer it is often no longer possible to carry out the same work as before [20]. Patients may face new employers and have to deal with other forms of work, duties and functions; they may face a drop in salary, unemployment or early retirement. Studies on this topic show contradictory findings. Usually no clear association can be demonstrated between employment or unemployment and the levels of anxiety and depression in patients $[2,11,13,21]$. According to a recent investigation by Bailey et al., the patients who are unemployed have a 4 times higher risk of depression than patients who are in full or part-time employment or are retired, or patients who are housewives [22].

In contrast to the frequently discussed issue of developmental disorders in children of mothers with breast cancer $[23,24]$, the impact of having children on the patients' levels of psychological stress has rarely been studied. In the study of Bailey et al., having children or having other major care-giving roles was found to be a risk factor for depression. Bloom et al. reported that patients' level of depression were lower if they had a child at home [22, 25]. In their recent study, Erim et al. found no association between having children and anxiety or depression [12]. When the age of the children was also factored into the study, Krauss et al. found anxiety and stress disorders to be higher in patients who had underage children [5]. In their study, Ernst et al. found that the presence of underage children had no impact on psychological stress levels of cancer patients [26], while Götze et al. even reported a poorer quality of life for women with children aged 17 and above [27].

The aim of this study was to map the levels of psychological stress (anxiety and depression) in breast cancer patients in the 1st year after diagnosis and correlate these levels with the factors "employment" and "parenthood" and to investigate whether there were any associations between these variables.

\section{Methods \\ $\nabla$}

This study was done as part of a randomised multi-centre study on the effectiveness of psychodynamic short-term psychotherapy in depressive breast cancer patients, carried out at the universities of Leipzig and Mainz [28]. In addition to the inclusion criteria of the main study (breast cancer in the curative stage with no diagnosis of distant metastasis and linguistic/cognitive ability to participate in the study), the inclusion criterion for this study included patient age (between 18 and 64 years). This study used a subset of data from the main study referred to above, in which all breast cancer patients treated between 2007 and 2012 in various co-operating facilities in Leipzig (several gynaecological departments and breast centres, one outpatient radiation clinic) were approached by investigators from the Leipzig study centre. Socio-demographic data (including employment status, 


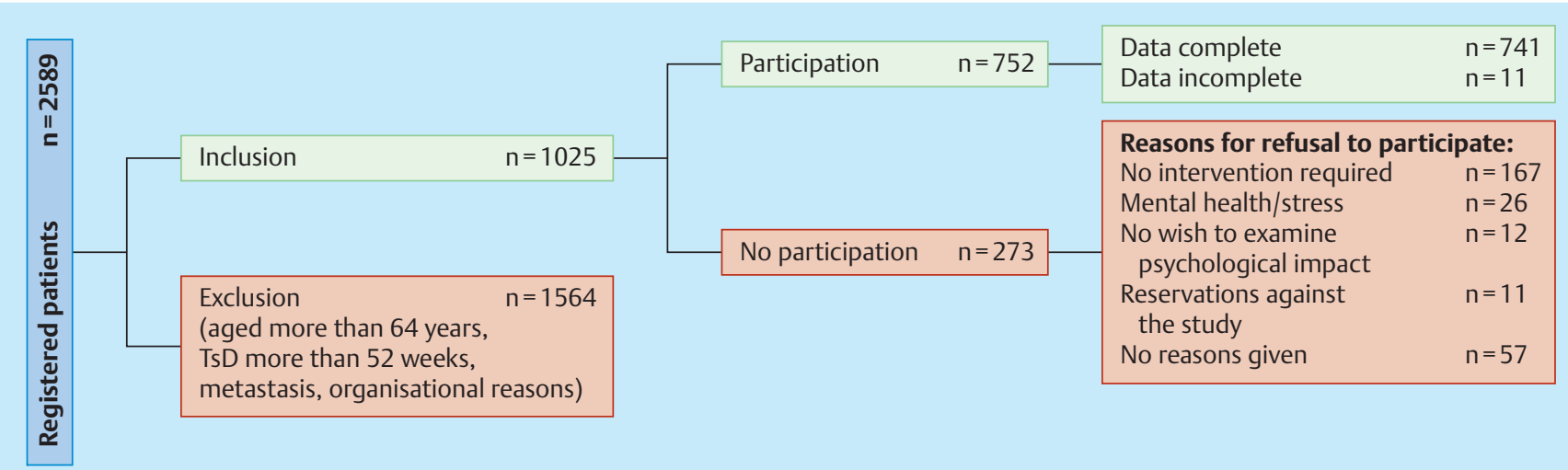

Fig. 1 Patient recruitment, $\mathrm{n}=$ number of patients.

children's age) was collected during the patient survey; medical data was obtained from the patients' medical records. All contacted patients were informed of the goal and aims of the study and were advised that participation in the study was voluntary. Written consent to participate in the study was obtained for all patients.

To investigate the level of psychological stress and correlate it with employment and parenthood in the 1st year after diagnosis, the study included all women between the age of 18 and 64 with breast cancer diagnosed not more than 1 year before. The data provided by the patients about the month in which they were diagnosed was used to calculate the period elapsed until the date of the survey (in weeks, the 1st day of the month was taken as the basis).

For the variable "children", patients were grouped as follows: women without children, women with at least one child below the age of 16 years, and women with children older than 16 years. From this age onwards, most children, even if they are still legally minors, are largely independent, so that patients have fewer duties of care and assistance, which should also impact on their level of psychological stress.

For multivariate analysis, the TsD, based on the empirical distribution in the study group (mean TsD $=13.1$ weeks), was dichotomised into one group with a TsD of 0-3 months and a 2nd group with a TsD of 4-12 months. Dichotomisation of the variable "employment" was done, following the categorisations using in other studies $[13,21,29]$, with women grouping either into one group of women who were not employed and a 2nd group consisting of all the other patients.

\section{Instruments}

Psychological stress was determined using the Hospital Anxiety and Depression Scale (HADS) [30]. HADS is a valid instrument to record anxiety and depression in patients with physical disease $[30,31]$ and is often used when screening for psychological stress in cancer patients. The questions do not focus on somatic symptoms, thereby preventing false-positive results. The reliability and validity of the scale has been proven several times [32-35]. Anxiety and depression are recorded using 2 subscales [30,31], each with 7 questions. Values between 0 and 3 are allocated using a 4-point rating scale (maximum subscale score: 21 points). The cut-off points recommended by the authors of the scale are $\geq 8$ points for marginal and $\geq 11$ points for clinically relevant levels of anxiety and depression. Lower marginal values have also been discussed $[32,34,36]$. The reference values for anxiety (mean in women: 5.0) and depression (mean in women: 4.7 ) in the general population were provided by Hinz and Brähler in an extensive study with $n=4410$ participants [10].

\section{Statistical Analysis \\ $\nabla$}

Data were analysed using SPSS 15.0. The level of significance was set at $\alpha=0.05$. Initial analysis of associations between the variables "TsD", "employment" and "parenthood" and anxiety or depression were done using bivariate correlation (Spearman's test) and one-way ANOVA. Subsequently univariate multi-factorial analysis of variance was carried out separately for anxiety and depression to determine the potential reciprocal effects of the variables "TsD", “employment" and "parenthood". Patient age was included in the analysis as a covariate. To offer a better overview and comparability of group sizes, the variables "employment" and "TsD" were investigated using two-way ANOVA.

\section{Results}

\section{Study population}

In the period under investigation a total of 2589 breast cancer patients were contacted by the Leipzig Study Centre. Of the 1025 patients who complied with the study criteria 273 patients (27\%) refused to participate in the study. Reasons cited by patients who did not wish to take part in the study included "no need for psychotherapy", "too much stress or overwork", "no wish to examine the psychological impact of cancer even in a therapeutic setting" and "reservations against the study". For 11 (1\%) of the participating patients, the HADS data were incomplete. They were excluded from the analysis. The remaining 741 datasets provided the basis for analysis. Based on the number of patients who complied with the inclusion criteria, the response rate was $72 \%$ (๑ Fig. 1 ).

The composition of the study population is shown in $\bullet$ Table $\mathbf{1 .}$ The majority of patients was more than 40 years old $(n=682$; $92.1 \%)$. Most women had children of their own aged more than 16 years $(n=494 ; 66.6 \%)$. The majority of surveyed patients were employed ( $n=470 ; 63.6 \%$ ) or retired $(n=150 ; 20.2 \%) .84$ patients (11.3\%) were unemployed. At the time of the survey, most pa- 
tients ( $n=509 ; 68.7 \%$ ) had been diagnosed with breast cancer not more than 3 months previously. The mean TsD was 13 weeks.

\section{Psychological stress}

- Table 2 shows the level of anxiety or depression correlated to socio-demographic and disease-related variables. In the investigated study population, the mean score for anxiety was 6.94 (SD 4.08) and 4.40 for depression (SD 3.67). $23 \%$ of patients had subscale scores of between 8 and 10, i.e. scores were on the threshold to being clinically relevant; $19 \%$ of patients had scores $>10$, indicating clinically relevant levels of anxiety. $10 \%$ of women had marginal scores for depression, and $8 \%$ had clinically relevant levels of depression. There were significant differences in anxiety levels between groups for the variables "parenthood" $(\mathrm{p}=0.04), \quad \mathrm{TsD} \quad(\mathrm{p}=0.02)$ and "previous psychotherapy" $(p<0.001)$. There were significant differences in depression levels for the variables "employment" $(\mathrm{p}=0.05)$, "previous psychotherapy" ( $p<0.001)$ and "type of surgery" $(p<0.01)$.

\section{Lower level of anxiety but no changes in level}

of depression over time in the 1st year after diagnosis

Correlation analysis showed a highly significant relation between TsD and anxiety with the variables trending slightly in opposite directions $(r=-0.10 ; p<0.001)$. No relation was found between depression and TsD $(r=0.02 ; \mathrm{p}=0.66)$. After TsD had been subdivided into groups, the level of anxiety dropped as TsD increased (the mean dropped from 7.57 to $5.8, p=0.02$; cf. $\bullet$ Fig. 2). Only women with a TsD of 10-12 months showed slightly increased levels of anxiety again (6.06). The mean for depression in all women ranged around a narrow mean (mean 4.17-4.9), without a perceivable correlation with TsD.

\section{Increased levels of depression in unemployed} breast cancer patients and increased levels of anxiety in breast cancer patients with young children When the employment status of breast cancer was investigated, the highest levels of anxiety were recorded for unemployed patients (7.7; $\odot$ Table 2). The findings for women who had retired before the age of 65 years were significantly lower (6.6) and were closer to the levels recorded for employed patients (6.73-7.02). In the group of employed patients, it made no difference whether the employment was full-time or part-time; the anxiety levels for both groups were approximately the same. The lowest anxiety levels were found in the group of housewives (6.07). Unemployed breast cancer patients were also the group affected strongest by depression (5.27). Retired patients and patients in full or parttime employment did not differ much with regard to the calculated mean for depression (4.14-4.51). Again, the group of housewives had the lowest levels (3.07). The difference between groups was not significant for anxiety $(\mathrm{p}=0.22)$ but the difference for depression was significant $(\mathrm{p}=0.05)$.

Parenthood as such (without taking account of the child's age) was not found to be significantly associated with psychological stress. The levels of anxiety for women with children were not significantly higher (7.01) than for women without children $(6.42 ; p=0.20)$. The levels of depression were similar $(p=0.64)$ for women with (4.37) and without children (4.57). However, when the age of the children was also taken into account, then mothers with children below the age of 16 years had the highest levels of anxiety (7.84). In contrast, the means for women without children and for mothers of older children were both lower. The difference in anxiety levels between patients with children
Table 1 Socio-demographic and disease-related characteristics of the study population ( $n=741$ breast cancer patients).

\begin{tabular}{|c|c|c|}
\hline & $\mathbf{n}$ & $\%$ \\
\hline \multicolumn{3}{|l|}{ Patient age } \\
\hline \multicolumn{3}{|l|}{ Mean (SD) $53.0(8.3$ ) years } \\
\hline $18-39$ & 59 & 8.0 \\
\hline $40-59$ & 500 & 67.5 \\
\hline $60-64$ & 182 & 24.6 \\
\hline \multicolumn{3}{|l|}{ Employment } \\
\hline Unemployed & 84 & 11.3 \\
\hline Full-time employment & 345 & 46.6 \\
\hline Part-time employment & 125 & 16.9 \\
\hline Retired & 150 & 20.2 \\
\hline Housewife & 27 & 3.6 \\
\hline In education & 1 & 0.1 \\
\hline No data available & 9 & 1.2 \\
\hline \multicolumn{3}{|l|}{ Parenthood } \\
\hline No children & 88 & 11.9 \\
\hline Children $<16$ years & 95 & 12.8 \\
\hline Children $\geq 16$ years & 558 & 75.3 \\
\hline \multicolumn{3}{|l|}{ Education } \\
\hline University entrance diploma & 209 & 28.2 \\
\hline Other & 532 & 71.8 \\
\hline \multicolumn{3}{|l|}{ In a steady relationship } \\
\hline Yes & 607 & 81.9 \\
\hline No & 134 & 18.1 \\
\hline \multicolumn{3}{|c|}{ Prior history of psychotherapy } \\
\hline Yes & 137 & 18.5 \\
\hline No & 591 & 79.8 \\
\hline No data available & 13 & 1.8 \\
\hline \multicolumn{3}{|l|}{ Time since diagnosis (TsD) } \\
\hline \multicolumn{3}{|l|}{ Mean (SD) 13.1 (11.5) weeks } \\
\hline$<1$ month & 161 & 21.7 \\
\hline $2-3$ months & 333 & 44.9 \\
\hline $4-6$ months & 110 & 14.8 \\
\hline 7-9 months & 59 & 8.0 \\
\hline $10-12$ months & 63 & 8.5 \\
\hline No data available & 15 & 2.0 \\
\hline \multicolumn{3}{|l|}{ Type of surgery } \\
\hline Ablation & 169 & 22.8 \\
\hline Breast-conserving surgery & 473 & 63.8 \\
\hline No surgery & 17 & 2.3 \\
\hline No data available & 82 & 11.1 \\
\hline \multicolumn{3}{|l|}{ Tumour stage (UICC) } \\
\hline 0 & 59 & 8.0 \\
\hline I & 286 & 38.6 \\
\hline II & 224 & 30.2 \\
\hline III & 58 & 7.8 \\
\hline No data available & 114 & 15.4 \\
\hline \multicolumn{3}{|l|}{ Current therapy } \\
\hline Surgery & 432 & 58.3 \\
\hline Chemotherapy & 97 & 13.1 \\
\hline Radiotherapy & 189 & 25.5 \\
\hline Endocrine therapy & 91 & 12.3 \\
\hline Other & 16 & 2.2 \\
\hline None & 23 & 3.1 \\
\hline
\end{tabular}

below the age of 16 years and women without children was statistically significant $(p=0.04)$. When depression was investigated, women with children above the age of 16 years were found to have the lowest levels. The levels of depression were somewhat higher for women without children or women with younger children. Overall, depression levels ranged around a narrow mean (4.33-4.6) and the differences between groups were not significant $(\mathrm{p}=0.72)$. 
No interaction effect between "time since diagnosis", "employment" or "parenthood" and anxiety or depression

Analysis of variance was done to determine the aggregate effect of the investigated variables and potential reciprocal effects. Determination of variance for anxiety based on the investigated variables was $\mathrm{R}^{2}=4.2 \%$ (cf. @ Table 3 ). The variables “TsD” ( $\mathrm{p}=0.04$ ), "employment" $(p=0.03)$ and "parenthood" $(p=0.03)$ were found to have significant main effects on anxiety. When controlled for patient age (covariate), no interaction effects between variables were found.

Similarly, determination of variance for depression based on the investigated variables was low, amounting to $\mathrm{R}^{2}=1.9 \%$ (cf. O Table 4). Overall, as in the previous individual tests, only employment had a significant main effect on depression $(p=0.01)$. Here again, no interaction effects were found between the investigated variables, even with age as a covariate.

\section{Discussion}

$\nabla$

This study aimed to analyse the relation between psychological stress and employment and parenthood, taking account of the time since diagnosis. The mean anxiety level for the study population in our study (6.94; SD 4.08) was higher than the level re-

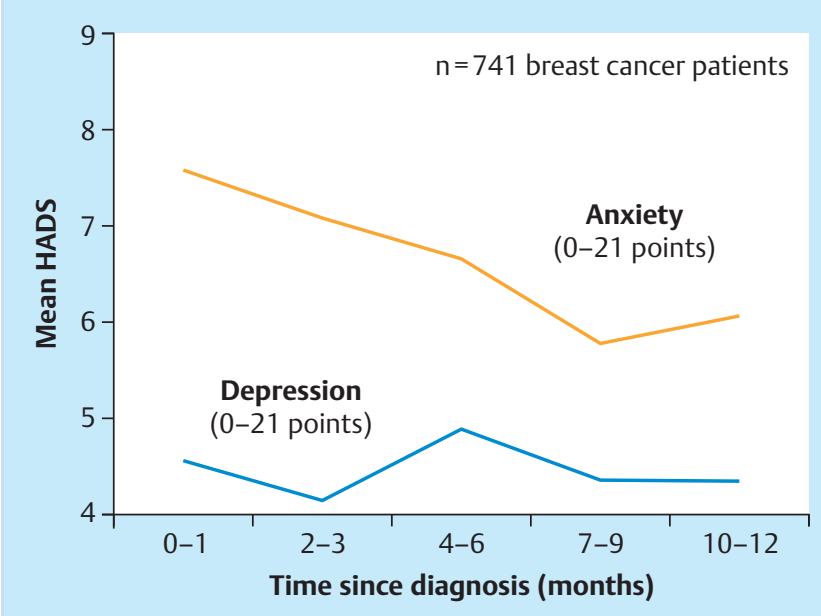

Fig. 2 Mean HADS score for anxiety and depression at various time-points after diagnosis.

ported for women in the general population in Germany (5.0; SD 3.6) [10]; however the mean depression levels (4.4; SD 3.67) were even slightly below the levels reported for the general female population in Germany (4.7; SD 3.9).

Table 2 Mean HADS score for anxiety and depression on a scale of 0-21 points for medical and socio-economic variables $(n=741)$.

\begin{tabular}{|c|c|c|c|c|}
\hline Predictor & Expression & $\begin{array}{l}\text { Mean HADS score } \\
\text { for anxiety }\end{array}$ & $\begin{array}{l}\text { Mean HADS score } \\
\text { for depression }\end{array}$ & Significance \\
\hline \multirow[t]{4}{*}{ Patient age } & correlation & & & $\begin{array}{l}A: r=-0.05 ; p=0.23 \\
D: r=0.01 ; p=0.76\end{array}$ \\
\hline & $18-39$ & 7.02 & 4.63 & $A: F=2.90 p=0.06$ \\
\hline & $40-59$ & 7.16 & 4.44 & $D: F=0.42 ; p=0.66$ \\
\hline & $60-64$ & 6.31 & 4.20 & \\
\hline \multirow[t]{5}{*}{ Employment } & unemployed & 7.70 & 5.27 & $A: F=1.44 ; p=0.22$ \\
\hline & full-time employment & 7.02 & 4.34 & $D: F=2.34 ; p=0.05$ \\
\hline & part-time employment & 6.73 & 4.14 & \\
\hline & retired & 6.60 & 4.51 & \\
\hline & housewife/in education & 6.07 & 3.07 & \\
\hline \multirow[t]{3}{*}{ Parenthood } & no children & 6.42 & 4.57 & $A: F=3.10 ; \mathbf{p}=\mathbf{0 . 0 4}$ \\
\hline & children $<16$ years & 7.84 & 4.60 & $D: F=0.33 ; p=0.72$ \\
\hline & children $\geq 16$ years & 6.87 & 4.33 & \\
\hline \multirow[t]{2}{*}{ Education } & university entrance diploma & 7.00 & 4.29 & $A: F=0.16 ; p=0.69$ \\
\hline & other & 6.92 & 4.44 & $D: F=0.23 ; p=0.63$ \\
\hline \multirow[t]{2}{*}{ In a steady relationship } & yes & 6.94 & 4.30 & $A: F=0.00 ; p=1.00$ \\
\hline & no & 6.94 & 4.81 & $D: F=2.05 ; p=0.15$ \\
\hline \multirow[t]{2}{*}{ Previous psychotherapy } & yes & 8.65 & 5.65 & $A: F=30.10 ; p<0.001$ \\
\hline & no & 6.57 & 4.12 & $D: F=19.80 ; p<0.001$ \\
\hline \multirow[t]{7}{*}{ Time since diagnosis (TsD) } & Correlation & & & $A: r=-0.14 ; p<0.001$ \\
\hline & & & & $D: r=0.02 ; p=0.66$ \\
\hline & $<1$ month & 7.57 & 4.55 & $A: F=3.10 ; \mathbf{p}=\mathbf{0 . 0 2}$ \\
\hline & $2-3$ months & 7.08 & 4.17 & $D: F=0.91 ; p=0.46$ \\
\hline & 4-6 months & 6.66 & 4.90 & \\
\hline & 7-9 months & 5.80 & 4.37 & \\
\hline & $10-12$ months & 6.06 & 4.37 & \\
\hline \multirow[t]{3}{*}{ Type of surgery } & ablation & 7.25 & 4.96 & $A: F=1.16 ; p=0.32$ \\
\hline & breast-conserving & 6.76 & 4.05 & $D: F=5.50 ; p<0.01$ \\
\hline & no surgery & 7.59 & 5.82 & \\
\hline \multirow[t]{4}{*}{ Tumour stage (UICC) } & 0 & 6.14 & 3.61 & $A: F=0.86 ; p=0.46$ \\
\hline & 1 & 6.99 & 4.06 & $D: F=1.56 ; p=0.20$ \\
\hline & ॥ & 6.76 & 4.39 & \\
\hline & III & 7.14 & 4.83 & \\
\hline
\end{tabular}

r: correlation coefficient; F: F-value; p: probability; significance and mean of the groups which differ significantly are indicated in bold; A: anxiety; D: depression. 
Table 3 Analysis of variance for anxiety (HADS).

\begin{tabular}{|llll|} 
& F & P & $\begin{array}{l}\text { Partial } \\
\text { eta-squared }\end{array}$ \\
\hline Corrected model & 2.60 & $\mathbf{< 0 . 0 1}$ & 0.04 \\
\hline TsD & 4.31 & $\mathbf{0 . 0 4}$ & 0.01 \\
\hline Employment & 4.52 & $\mathbf{0 . 0 3}$ & 0.01 \\
\hline Parenthood & 3.45 & $\mathbf{0 . 0 3}$ & 0.01 \\
\hline Patient age (covariate) & 0 & 0.99 & 0 \\
\hline
\end{tabular}

$R^{2} 0.042$ (corr. $R^{2} 0.026$ ); bold $=p$-value $<0.05$

This study demonstrated a connection between anxiety and TsD in breast cancer patients. Even if a direct development over time could not be shown using cross-sectional studies, the higher levels recorded for women with a shorter TsD do appear to indicate that anxiety levels drop during the course of the first year after diagnosis. This is confirmed by the findings of previous studies $[15,16,37,38]$ which demonstrated a constant decrease in anxiety levels in longitudinal analysis. The drop in depression levels reported in previous prospective investigations could not be confirmed by our study. In our study, women had constantly low levels of depression at all time-points after diagnosis ( Table $\mathbf{1}$ ).

It was interesting that patients with a TsD of approximately 1 year (10-12 months) still reported higher levels of anxiety compared to women in representative population studies. The studies by Schwarz et al. [15] and Vahdaninia et al. [16] showed similar results. Here too, the levels of anxiety of breast cancer patients at 12 and 18 months after diagnosis continued to be higher than those of the general population. One explanation for the development of psychological stress was given by both Wittchen et al. [39] and Penninx et al. [40], who reported that anxiety disorders tend to take a chronic course with a longer mean duration compared to depressive disorders. One reason for the high anxiety levels 10-12 months after diagnosis could also be a selection bias in our study population. Anxious women who independently volunteered to take part in the study 1 year after diagnosis could have increased the proportion of anxious patients for this study period.

Unemployment was found to be associated with high levels of depression in breast cancer patients. In accordance with the results of the study of Bailey et al. [22] and Mahar et al. [41], unemployed women were most strongly affected by depression. Unemployment leads to social isolation and reduced self-esteem; the daily tasks and routines which being in work imposes on the day's structure are lacking for these women. This can increase the risk for depression. This does not apply to patients who are housewives or retired. Lower levels of depression were found in these two groups, both in our study ( $\odot$ Table 1 ) and in the study by Bailey et al. The extent of employment (full or part-time) did not have an impact on the level of psychological stress in our study. Our study found no evidence that having children per se played an important role for the level of psychological stress. However, the age of the children was significant. Anxiety levels were higher in women with children below the age of 16 years. The anxiety levels of mothers of older children were as low as those of women without children. This confirms the findings of Krauß et al. [5], who also reported that underage children were a stress factor. The issue whether patients will be able to continue performing their parental duties, particularly when caring for younger children who are more dependent on them, could be one of the rea-
Table 4 Analysis of variance for depression (HADS).

\begin{tabular}{|c|c|c|c|}
\hline & $\mathbf{F}$ & $\mathbf{p}$ & $\begin{array}{l}\text { Partial } \\
\text { eta-squared }\end{array}$ \\
\hline Corrected model & 1.17 & 0.30 & 0.02 \\
\hline TsD & 0.93 & 0.34 & 0.00 \\
\hline Employment & 6.65 & 0.01 & 0.01 \\
\hline Parenthood & 2.12 & 0.12 & 0.01 \\
\hline Patient age (covariate) & 1.20 & 0.27 & 0.00 \\
\hline
\end{tabular}

$R^{2} 0.019$ (corr. $R^{2} 0.003$ ); bold $=p$-value $<0.05$

sons for these levels of anxiety. No connection was found between depression levels and parenthood.

The failure by many studies to take account of children's age [12, $22,25]$ could be the reason for the contradictory findings about the importance of children on maternal psychological stress.

Psycho-oncological treatment now plays an important role in the care of tumour patients. As has been discussed in other contexts [42], psychotherapeutic co-treatment is recommended as a corrective against the chronification of psychiatric disorders. Various care concepts for the use of psycho-oncological treatment are discussed in the literature $[43,44]$. Early recognition of patients at risk is essential. The findings of our study about special risk factors could contribute to targeted psycho-oncological care. The connection between parenthood, employment status and anxiety and depression were investigated using data from a large study population. Although the study was designed as a crosssectional study, interviewing patients early after diagnosis made it possible to demonstrate differences in psychological stress levels of women at various points in time during the 1st year after diagnosis. To support our results, longitudinal studies are needed to investigate the impact of time on psychological stress, taking account of the resources or risk factors present in the patients' social and working environment.

With regard to the limitations of this study, it is important to note that only patients in a curative stage of disease were included in the study. Our findings can therefore not be generalised and cannot be applied to all breast cancer patients, particularly not to patients in advanced stages of disease.

The information obtained about employment status and parenthood only serve to explain a small part of the total variance in anxiety (4.2\%) and depression (1.9\%) levels. One reason could be that the only factors investigated in this study were the presence or absence of children, the patient's employment status and the time since diagnosis. Other potentially relevant factors such as the patient's current physical condition and functional status and the patient's previous psychiatric history were not the object of this study.

\section{Conclusion \\ $\nabla$}

The longer the time since diagnosis, the more the level of psychological stress converged with the level of psychological stress in the general population. Physicians and clinical staff should pay more attention to signs of psychological stress in patients in the period immediately after diagnosis and when patients undergo acute therapy. Psycho-oncological treatment may be indicated at these times. It is important to be aware that anxiety levels of breast cancer patients are still significantly higher than in the general population in Germany even 1 year after diagnosis. 
The study showed that parenthood as such was not associated with psychological stress in breast cancer patients, but that women with younger children reported higher levels of anxiety. While the level of depression in breast cancer patients 1 year after diagnosis was approximately the same as in the general population, unemployed patients suffered higher levels of depression and should receive particular attention.

\section{Conflict of Interest}

$\nabla$

This study reports some of the results of the randomised clinical study "Effectiveness of psychodynamic short-term psychotherapy for depressive disorders in breast cancer patients" which received financial support from German Cancer Aid e.V. (reference number: 109379/109381) between 2007 and 2012. There were no financial or personal relations to any third persons whose interests could be affected by the contents of this manuscript.

\section{References}

1 Robert Koch-Institut. Verbreitung von Krebserkrankungen in Deutschland. Entwicklung der Prävalenz zwischen 1990 und 2010. Beiträge zur Gesundheitsberichtserstattung des Bundes. Berlin: RKI; 2010

$2 \mathrm{Kim} \mathrm{SH}$, Son BH, Hwang SY et al. Fatigue and depression in disease-free breast cancer survivors: prevalence, correlates, and association with quality of life. J Pain Symptom Manage 2008; 35: 644-655

3 Schmied B, Reitsamer R. Sexual function in breast cancer patients with different adjuvant medical treatment. Geburtsh Frauenheilk 2012; 72: A24

4 Mehnert A, Koch U. Psychological comorbidity and health-related quality of life and its association with awareness, utilization, and need for psychosocial support in a cancer register-based sample of long-term breast cancer survivors. J Psychosom Res 2008; 64: 383-391

5 Krauss O, Ernst J, Kuchenbecker D et al. Prädiktoren psychischer Störungen bei Tumorpatienten: Empirische Befunde. Psychother Psych Med 2007; 57: 273-280

6 Hopwood P, Sumo G, Mills J et al. The course of anxiety and depression over 5 years of follow-up and risk factors in women with early breast cancer: results from the UK Standardisation of Radiotherapy Trials (START). Breast 2010; 19: 84-91

7 Smith AB, Selby PJ, Velikova G et al. Factor analysis of the Hospital Anxiety and Depression Scale from a large cancer population. Psychol Psychother 2002; 75: 165-176

8 Wittchen $H U$, Muller N, Pfister $H$ et al. Affektive, somatoforme und Angststörungen in Deutschland - Erste Ergebnisse des bundesweiten Zusatzsurveys „Psychische Störungen“. Gesundheitswesen 1999; 61: 216-222

9 Stordal E, Kruger MB, Dahl NH et al. Depression in relation to age and gender in the general population: the Nord-Trondelag Health Study (HUNT). Acta Psychiatr Scand 2001; 104: 210-216

10 Hinz A, Brahler E. Normative values for the Hospital Anxiety and Depression Scale (HADS) in the general German population. J Psychosom Res 2011; 71: 74-78

11 Aschenbrenner A, Härter $M$, Reuter $K$ et al. Prädiktoren für psychische Beeinträchtigungen und Störungen bei Patienten mit Tumorerkrankungen - Ein systematischer Überblick empirischer Studien. Z Med Psychol 2003; 12: 15-28

12 Erim Y, Beckmann M, Hoffmann O et al. Prädiktoren psychischer Belastung bei Brustkrebspatientinnen - Worauf sollten Ärzte und Pflegekräfte in der onkologischen Praxis achten? Geburtsh Frauenheilk 2011; 71: 285-291

13 Ell K, Sanchez K, Vourlekis B et al. Depression, correlates of depression, and receipt of depression care among low-income women with breast or gynecologic cancer. J Clin Oncol 2005; 23: 3052-3060

14 Lueboonthavatchai P. Prevalence and psychosocial factors of anxiety and depression in breast cancer patients. J Med Assoc Thai 2007; 90: 2164-2174

15 Schwarz R, Krauss O, Hockel M et al. The course of anxiety and depression in patients with breast cancer and gynaecological cancer. Breast Care 2008; 3: 417-422
16 Vahdaninia M, Omidvari S, Montazeri A. What do predict anxiety and depression in breast cancer patients? A follow-up study. Soc Psychiatry Psychiatr Epidemiol 2010; 45: 355-361

17 Berth H, Förster P, Brähler E et al. Arbeitslosigkeit und Gesundheit - Ergebnisse der Sächsischen Längsschnittstudie. In: Mühlpfordt S, Mohr G, Richter P, Hrsg. Erwerbslosigkeit: Handlungsansätze zur Gesundheitsförderung. Lengerich: Papst Science Puplishers; 2011: 35-53

18 Berth H, Förster P, Stöbel-Richter Y et al. Arbeitslosigkeit und psychische Belastung. Ergebnisse einer Längsschnittstudie 1991 bis 2004. Z Med Psychol 2006; 15: 111-116

19 Albani C, Blaser G, Brahler E. Gesundheitsberichterstattung der Krankenkassen, Gesundheitsreport der Techniker Krankenkasse mit Daten und Fakten bei Arbeitsunfähigkeit und Arzneiverordnungen. Schwerpunktthema: psychische Störungen. Psychotherapeut 2008; 53: 456460

20 Mehnert A. Employment and work-related issues in cancer survivors. Crit Rev Oncol Hematol 2011; 77: 109-130

21 Casso D, Buist DSM, Taplin S. Quality of life of 5-10 year breast cancer survivors diagnosed between age 40 and 49 . Health Qual Life Outcomes 2004; $2: 25$

22 Bailey EH, Perez M, Aft RL et al. Impact of multiple caregiving roles on elevated depressed mood in early-stage breast cancer patients and same-age controls. Breast Cancer Res Treat 2010; 121: 709-718

23 Romer G, Schulte-Markwort M, Riedesser P. Kinder körperlich kranker Eltern am Beispiel Kinder krebskranker Mütter. Geburtsh Frauenheilk 2002; 62: 537-542

24 Ernst J, Weissflog G, Brahler E et al. Depressivität bei 11- bis 17-jährigen Kindern krebskranker Eltern im Verlauf und Abhängigkeit zur elterlichen Belastung. Prax Kinderpsychol Kinderpsychiat 2012; 61: 432 446

25 Bloom JR, Stewart SL, Johnston $M$ et al. Intrusiveness of illness and quality of life in young women with breast cancer. Psychooncology 1998; 7: 89-100

26 Ernst J, Götze H, Krauel Ket al. Psychological distress in cancer patients with underage children: gender-specific differences. Psychooncology 2013; 22: 823-828

27 Götze H, Ernst J, Krauss $O$ et al. Risiko oder Schutz? - Der Einfluss der Elternschaft auf die Lebensqualität von Krebspatienten. Z Psychosom Med Psychother 2007; 53: 355-372

28 Zwerenz R, Beutel ME, Imruck BH et al. Efficacy of psychodynamic short-term psychotherapy for depressed breast cancer patients: study protocol for a randomized controlled trial. BMC Cancer 2012; 12: 578

29 Plaisier I, de Bruijn JGM, Smit JH et al. Work and family roles and the association with depressive and anxiety disorders: Differences between men and women. J Affect Disord 2008; 105: 63-72

30 Zigmond AS, Snaith RP. The Hospital Anxiety and Depression Scale. Acta Psychiatr Scand 1983; 67: 361-370

31 Herrmann C, Buss U, Snaith RP. HADS-D Hospital Anxiety and Depression Scale - Deutsche Version. Bern: Huber; 1995

32 Alexander S, Palmer C, Stone PC. Evaluation of screening instruments for depression and anxiety in breast cancer survivors. Breast Cancer Res Treat 2010; 122: 573-578

33 Bjelland I, Dahl AA, Haug TT et al. The validity of the Hospital Anxiety and Depression Scale: an updated literature review. J Psychosom Res 2002; 52: 69-77

34 Härter M, Woll S, Wunsch A et al. Screening for mental disorders in cancer, cardiovascular and musculoskeletal diseases. Comparison of HADS and GHQ-12. Soc Psychiatry Psychiatr Epidemiol 2006; 41: 56-62

35 Herrmann $C$. International experiences with the hospital anxiety and depression scale - a review of validation data and clinical results. J Psychosom Res 1997; 42: 17-41

36 Singer S, Kuhnt S, Gotze H et al. Hospital anxiety and depression scale cutoff scores for cancer patients in acute care. Br J Cancer 2009; 100: 908-912

37 Burgess C, Cornelius V, Love $S$ et al. Depression and anxiety in women with early breast cancer: five year observational cohort study. BMJ 2005; 330: 702-705

38 Den Oudsten BL, Van Heck GL, Van der Steeg AF et al. Second operation is not related to psychological outcome in breast cancer patients. Int J Cancer 2010; 126: 1487-1493

39 Robert Koch-Institut, Hrsg. Angststörungen. Gesundheitsberichterstattung des Bundes. Heft 21. Berlin: RKI; 2010

40 Penninx BW, Nolen WA, Lamers $F$ et al. Two-year course of depressive and anxiety disorders: results from the Netherlands Study of Depression and Anxiety (NESDA). J Affect Disord 2011; 133: 76-85 
41 Mahar KK, Brintzenhofeszoc K, Shields JJ. The impact of changes in employment status on psychosocial well-being: A study of breast cancer survivors. J Psychosoc Oncol 2008; 26: 1-17

42 Siedentopf $F$. Chronic pain syndromes in gynaecological practice: endometriosis and fibromyalgia. Geburtsh Frauenheilk 2012; 72: 10921098
43 Reuter K. Psychoonkologie: Stellenwert, Prinzipien und Behandlungsansätze. Geburtsh Frauenheilk 2011; 71: R2-R15

44 Rehse B, Reuter E, Schneider B et al. Inanspruchnahme und Akzeptanzvergleich eines psychoonkologischen Nachsorgeangebots bei von Brustkrebs betroffenen Frauen. Geburtsh Frauenheilk 2008; 68: 907914

Deutschsprachige Zusatzinformationen online abrufbar unter: www.thieme-connect.de/ejournals/toc/gebfra. 